\title{
Relações com os estudantes e preparação para o magistério superior: visões dos docentes iniciantes
}

The relationship with students and on the preparation for higher education teaching: views of beginner teachers

\section{Resumo}

texto apresenta resultados de pesquisa que buscou identificar como docentes universitários percebem suas relações com os alunos a partir de seu ingresso na carreira e as possíveis contribuições que cursos de pós-graduação stricto sensu proporcionaram para seu exercício docente. A coleta de dados foi realizada através de entrevistas com 27 docentes iniciantes. A análise dos dados foi realizada à luz do referencial teórico de Marcelo Garcia (2009), Pimenta e Anastasiou (2008), Zabalza (2004), dentre outros. Os professores reconheceram que as relações com os estudantes precisam estar mediadas pelo conhecimento não excluindo, porém, questões afetivas. Eles entendem que o protagonismo do estudante universitário é fundamental na sua aprendizagem e o ensino por eles desenvolvido precisa privilegiar essa condição. Os professores reconhecem ainda que os PPG preparam para a pesquisa, mas afirmaram que a sala da aula exige conhecimentos próprios, não desenvolvidos na pós-graduação stricto sensu.

Palavras-chave: Educação superior. Docentes iniciantes. Formação docente.
Beatriz Maria Boéssio Atrib Zanchet Nadiane Feldkercher Helena Beatriz Mascarenhas de Souza Universidade Federal de Pelotas

\section{Abstract}

This paper presents results of a research was aimed at identifying how university teachers see the relations they establish with their students from the moment they enter in their career, and the contributions of the strict sensu graduate courses for their practice. The data collection was accomplished by semi-structured interviews with 27 beginning teachers. The data was analyzed based in Marcelo Garcia (2009), Pimenta and Anastasiou (2008) and Zabalza (2004), among others. It was possible to conclude that the teachers interviewed have recognized that the relationship with their students must be mediated by knowledge, as well as by affection. They believe that a prominent role is an essential feature for the university students' learning, and the teaching they provide must privilege such condition. They also recognize that graduate courses prepare for research, but, in their view, teaching demands specific types of knowledge not covered by strict sensu graduate courses.

Keywords: higher education. Beginning teachers. Teacher education. 


\section{Docência universitária: entre o ensino e a pesquisa}

Ao formular as políticas educativas, os governos têm anunciado entre suas metas fundamentais a expansão do ensino com qualidade. A mesma meta tem estado presente nos discursos dos gestores e dos órgãos responsáveis pela realização dos censos educacionais brasileiros, os quais sinalizam que a qualidade do ensino superior ainda não foi atingida. Os dados publicados do Censo da Educação Superior de 2010 "confirmam tendências e reforçam preocupações", conforme afirma matéria veiculada na mídia sob o título: Número de universitários aumenta, mas patamar ainda é baixo se comparado ao de outros países, e a qualidade está longe de ser satisfatória. (EDITORIAL, 2011 ). A matéria informa que o total de estudantes matriculados em algum curso de graduação já soma 6,4 milhões, o que representa uma alta de 110\% no período de uma década. No entanto, a taxa de escolarização no ensino superior brasileiro está bem abaixo de alguns países da América Latina, como o Chile e Argentina. A matéria alerta que "o Brasil precisa seguir no rumo da expansão da educação superior e, ao mesmo tempo, melhorar substancialmente sua qualidade, o que representa um desafio formidável."

A partir dos dados do Censo de 2010, observamos que no Brasil a expansão do ensino superior pela via da iniciativa privada alcançou $73 \%$ das matrículas. Na maioria das vezes, essa expansão se dá através de instituições que centram suas atividades no ensino e em que a qualidade do trabalho acadêmico, muitas vezes, não é condição fundamental de funcionamento. Mesmo assim, com custos mais baixos, representam uma ameaça na guerra da competitividade, levando as universidades públicas, que enfrentam a complexidade da pesquisa, a procurar formas de gestão próximas das empresas, incorporando lógicas de mercado que não faziam parte de sua constituição.

Esse tempo de expansão e interiorização é instigante para analisar o caso dos "jovens" recém-doutores e/ ou mestres que acorrem à carreira docente, na expectativa de encontrar um espaço de profissionalização. Realizaram seus cursos de mestrado e doutorado, aprendendo a trajetória da pesquisa e, em geral, aprofundaram um tema de estudo verticalmente, num processo progressivo de especialização. Quando se incorporam à educação superior nesses tempos de interiorização e massificação, descobrem que deles se exige uma gama maior de saberes, em especial para o exercício da docência, para o qual, na maioria das vezes, não estão preparados. Todavia, o artigo 66 da 
Lei de Diretrizes e Bases da Educação Nacional n 9394, de 20 de dezembro de 1996 (LDB, 1996) versa literalmente sobre a condição de preparação para o exercício da docência universitária, prescrevendo que, para o exercício do magistério superior, a "preparação" dos professores será desenvolvida nos Programas de Pós-Graduação (PPG) stricto sensu. Esses Programas privilegiam o desenvolvimento de habilidades para a pesquisa valorizadas na educação superior. Deste modo, os Programas de Pós-Graduação stricto sensu se constituíram no lugar privilegiado de formação dos docentes, baseando seus projetos pedagógicos na dimensão da pesquisa sem, em geral, se preocuparem com os saberes próprios do exercício da docência. Esses Cursos orientam-se fundamentalmente para estudos na perspectiva de um recorte especializado do conhecimento. Muito poucos são os que, de forma complementar, oferecem algum estudo no campo das ciências humanas e, em especial, da educação. Essa condição faz com que a maioria dos ingressantes na carreira do magistério, cada vez mais jovens e com expressiva titulação, não possua a mínima base dos conhecimentos profissionais para a docência.

É preciso levar em consideração que, embora estejam preparados para a pesquisa e nem tanto para assumir a docência, a maioria dos docentes universitários iniciantes, não começa sua prática do zero, pois, em sua vida de estudantes, conviveram com professores e aprenderam algo sobre como "dar aulas", conhecem alguns recursos pedagógicos que thes foram apresentados e que não podem ser desprezados. Têm portanto concepções sobre o que é ensinar e aprender.

Todavia, se percebe que a falta de formação faz com que se sintam desconhecedores de um campo conceitual que fundamente suas práticas docentes. Talvez essa seja uma das razões que os levem à imitação de outros professores que consideram modelos, dessa forma continuando com as práticas tradicionais que existem na docência universitária.

De maneira geral, é possível, então, afirmar que a formação exigida para os docentes universitários tem sido restrita ao conhecimento aprofundado da disciplina a ser ensinada. Seja esse um conhecimento prático, decorrente do exercício profissional, ou um conhecimento teórico, oriundo do exercício acadêmico, pouco ou nada tem sido exigido dos docentes em termos pedagógicos. Assim, podemos constatar que a graduação tem sido mantida por docentes titulados, cada vez mais jovens na carreira docente, que possuem 
uma significativa bagagem de conhecimentos específicos, mas com pequena preparação pedagógica.

Entendemos que a atividade de ensino exige conhecimentos teóricos e práticos que não se confundem com o conhecimento das disciplinas. Para ensinar, o domínio do conhecimento específico é condição necessária, mas não suficiente. Os professores universitários, sejam iniciantes ou mais experientes, como em qualquer outra profissão, teriam que possuir conhecimentos, habilidades e atitudes que sua tarefa exige para ser realizada com excelência.

Em geral, acredita-se que a pesquisa torna melhores os professores porque os ajuda a pensar, a duvidar e a compreender, todas essas qualidades importantes na docência. No entanto, não podemos tomar como verdade absoluta que um pesquisador qualificado será um bom professor; infelizmente, o ingresso na carreira docente de pesquisadores reconhecidos não transfere a competência e excelência destes no campo da pesquisa para o seu desempenho no campo do ensino. Segundo Zabalza:

[...] o que normalmente é avaliado nos concursos de ingresso e promoção são os méritos das pesquisas; o que os professores e seus departamentos tendem a priorizar por causa dos efeitos econômicos e do status são as atividades de pesquisa; o destino prioritário dos investimentos para formação do pessoal acadêmico, em geral, é orientado principalmente para a formação em pesquisa (muitas vezes, é administrado pelas pró-reitorias de pesquisa) e assim sucessivamente. (ZABALZA, 2004, p. 154).

A melhoria da prática pedagógica não requer somente a compreensão intelectual dos agentes implicados, mas fundamentalmente sua vontade de transformar as condições que constituem a cultura herdada. Torna-se importante, no contexto da iniciação dos docentes na carreira universitária, refletir sobre sua formação pedagógica', além de buscar compreender os processos que esses docentes vivenciam para construir saberes para o ensino. Dentre esses processos, privilegiamos nesse texto aqueles que dizem respeito às relações estabelecidas entre os professores e seus alunos nos primeiros anos da docência e as possíveis contribuições que cursos de pós-graduação stricto sensu proporcionaram para seu exercício docente. 


\section{O percurso investigativo: campo empírico, instrumentos e interlocutores}

primeiro delineamento do campo empírico foi através da definição das Universidades que poderiam participar da pesquisa. Para tal, consideramos como critérios: localização geográfica em relação à atuação dos pesquisadores participantes do grupo (Rio Grande do Sul e Paraná) e dependência administrativa (públicas e privadas). A partir desses critérios buscamos nas Universidades Federal de Pelotas (UFPel), Universidade do Vale do Rio dos Sinos (UNISINOS), Universidade Federal do Pampa (UNIPAMPA) e Universidade Federal do Paraná (UFPR) - Setor Litoral - a indicação de professores que poderiam constituir a amostra, através do contato com os coordenadores dos diferentes Cursos dessas Instituições de Ensino Superior (IES). Após apresentarmos a pesquisa, solicitamos aos coordenadores que nos fornecessem os nomes dos professores iniciantes - com até cinco anos na carreira docente universitária - e oriundos de diferentes profissões. No segundo momento, contatamos com os professores indicados para saber sobre sua disponibilidade para participar da pesquisa através de uma entrevista semiestruturada. Constituímos uma amostra, a partir da disponibilidade dos docentes, que contou com 27 professores $^{2}$ que atuam em diferentes Cursos $^{3}$.

A entrevista semiestruturada foi composta por vários eixos temáticos, como por exemplo: motivos/razões para ingressar na docência universitária (como se tornou professor universitário); experiências iniciais na profissão docente; formas de apoio encontradas na IES ou no Departamento ou no Curso; relação com os estudantes; lugar de formação do professor universitário; saberes específicos para a docência; relação entre as atividades de pesquisa e atividades da docência.

As questões foram elaboradas levando em consideração os estudos e a trajetória do grupo de pesquisa, como também as pesquisas da área, tais como as de Cunha (201 1) ao discutir a formação de professores universitários, as de Pimenta e Anastasiou (2008) ao se referirem à docência universitária, as de Zabalza (2004) nos seus estudos dos alunos universitários, as de Marcelo Garcia (2009) ao estudar o início da docência, entre outros.

A análise dos dados considerou os princípios da análise de conteúdo, pois esse enfoque constitui-se em um conjunto de técnicas de análise de comunicação "[...] visando obter, por procedimentos sistemáticos e objetivos de 
descrição do conteúdo das mensagens, indicadores que permitam a inferência de conhecimentos relativos às condições de produção/recepção destas mensagens." (BARDIN, 1979, p. 42).

Quanto às técnicas de tratamento da informação relativas aos dados qualitativos, após transcritas todas as entrevistas, valemo-nos da análise de conteúdo, para conhecer aquilo que estavam nas palavras sobre as quais nos debruçamos. (BARDIN, 1979). O objetivo da análise de conteúdo, conforme Bardin (1979, p. 46), "[...] é a manipulação de mensagens (conteúdo e expressão desse conteúdo), para evidenciar os indicadores que permitam inferir sobre uma outra realidade que não a da mensagem." Essa condição torna possível a definição de algumas categorias para análise que podem ser, a priori, estabelecidas.

A análise pretendeu decompor o texto das entrevistas, fragmentá-lo em seus elementos fundamentais, recortando-o na perspectiva da síntese que se buscava. Assim, as categorias foram sendo construídas e reconstruídas através da interrogação sobre os dados disponíveis.

Observamos que há uma convergência entre os autores que trabalham a conceituação do professor iniciante quando tratam do tempo de exercício de magistério, que vai de 1 a 5 anos de docência. Na pesquisa ora apresentada, que se refere ao professor do ensino superior, consideramos iniciante aquele docente com uma titulação que não o formou para o ensino (profissional liberal ou bacharel), com título de mestre e/ou doutor, com até cinco anos de experiência docente. Essas características se aplicaram a todos os nossos interlocutores.

\section{Professores iniciantes avaliando suas relações com os estudantes}

Conforme já anunciamos neste texto, a universidade tem passado por um processo de expansão acelerada e por uma crescente massificação nos últimos anos. Desse processo, decorre um aumento significativo do número de alunos e aumenta, também, a diversidade presente nas salas de aula. São diferentes culturas, experiências, saberes e classes sociais que convivem no mesmo espaço.

Como o acesso ao ensino superior representa uma possibilidade de ascensão social, também podemos inferir que a expectativa de ingresso nesse 
nível cresceu muito. Zabalza (2004, p. 182) explica que essa situação "[...] desestrutura a antiga concepção elitista da universidade e as condições de funcionamento atribuídas a ela." Atualmente, a educação superior já não se constitui em um privilégio social para poucas pessoas, tendo-se transformado em aspiração plausível para camadas cada vez mais amplas da população.

Ao nos referirmos à massificação, entendemos que outras variáveis, além do número de alunos, também interferem na sala de aula. Diz Zabalza (2004) que podemos pensar na necessidade de atender a grupos muito grandes; na maior heterogeneidade dos grupos; na pouca motivação pessoal para estudar; na necessidade de contratar novos professores; no retorno ao modelo clássico de aula para grupos com muitos alunos frente à possibilidade de implementar um procedimento mais individualizado; na menor possibilidade de responder às necessidades específicas de cada aluno; na menor possibilidade de organizar, em condições favoráveis, os períodos de práticas em contextos profissionais.

$\bigcirc$ que se percebe é que em universidades com grande número de alunos, precisa haver um aumento de esforços para manter um ensino de qualidade. Os alunos, em geral, ingressam na universidade com alguns interesses profissionais definidos e, não raras vezes, fazem certas exigências específicas à instituição e aos professores. Isso leva a IES, em alguns casos, a ampliar e a diversificar a oferta de formação, de maneira que se adapte melhor às expectativas diferenciadas dos seus coletivos.

Oestudante universitário é uma pessoa vivendo um período de formação. Nessa perspectiva, as relações que se estabelecem entre professores e alunos podem ser um aspecto fundamental para suas aprendizagens.

Libâneo (1993) afirma que as relações entre professor e estudantes - que envolvem as formas de comunicação, a afetividade, a emoção, as manifestações espontâneas, dentre outros aspectos - também compõem a organização do fazer docente. A percepção de que as relações entre alunos e professores envolvem outras dimensões que ultrapassam a transmissão do conteúdo precisa fazer parte do cotidiano docente, em especial dos professores que estão iniciando a carreira universitária, pois essas relações também ajudam os docentes iniciantes em seu processo de socialização. 
No diálogo com nossos entrevistados, procuramos entender como os professores iniciantes avaliavam as suas relações com os estudantes e que dificuldades encontravam para construílas.

Percebemos duas dimensões presentes em suas respostas: a) uma ligada a aspectos acadêmicos e b) outra ligada a aspectos pessoais.

No que se refere aos aspectos acadêmicos das relações professor e estudantes, alguns entrevistados disseram que: Só a minha explicação não é suficiente. O aluno tem que tentar fazer sozinho, ele tem que pegar os livros, pegar os cadernos e trabalhar sozinho um pouco. Eu procuro ensinar eles a chegarem nesse ponto. Eu explico, faço exemplos, dou exercícios para fazerem em casa e depois tiro as dúvidas de quem não conseguiu fazer. $O$ esclarecimento das dúvidas é para que consigam resolver sozinhos os próximos. (Professor 11) . Na mesma direção, anuncia: Eu me dou por satisfeito quando eles conseguem resolver sozinhos e de forma correta. (PROFESSOR 11 ). Essas expressões são afirmativas interessantes, pois, ao mesmo tempo que demonstram uma preocupação com a autonomia dos estudantes, podem esconder uma tentativa de torná-los os únicos responsáveis pelos seus processos de aprendizagem e sucesso acadêmico. Esta última concepção, conforme 162 Zabalza,

[...] costuma ser a primeira reação de muitos docentes em relação ao processo da aprendizagem dos estudantes: considerá-los como algo que não thes compete diretamente. Sobre essa consideração bastante defensiva, criou-se uma visão de aprendizagem como algo que depende do aluno e não do professor. Nós, professores, apenas ensinamos. (ZABALZA, 2004, p. 188).

Libâneo (1993, p. 249) refere que a "[...] interação professor-alunos é um aspecto fundamental da organização da 'situação didática', tendo em vista alcançar os objetivos do processo de ensino [...]", entendendo que o ensino só terá sentido se houver aprendizagem.

A ideia principal a esse respeito parece ser a que concebe a universidade como instituição de aprendizagem frente à ideia mais geral de entendê-la como instituição de ensino. No entanto, alertamos que uma preocupação essencial para quem desenvolve seu trabalho formativo na universidade, principalmente nos primeiros anos da docência, é a reconsideração constante dos processos e das estratégias por meio dos quais os estudantes chegam 
à aprendizagem. De acordo com Zabalza (2004, p. 189) "[...] somente a partir de um claro conhecimento desses processos estaremos em condições de poder aprimorá-los, ajustando para isso nossos métodos de ensino." Para alcançar os objetivos educativos, para ocorrer a interação, um ensino que vise à aprendizagem, ponderamos que são importantes as formas de comunicação adotadas pelo professor iniciante para atingir os estudantes.

Outro respondente disse que nas primeiras aulas tu conheces o aluno, tu vais desenvolvendo o conteúdo conforme o aluno. Não adianta o professor fazer um discurso lá na frente, falar linguagens, explicar ali o que o professor entende, quem tem que entender é o aluno. O professor é que tem que chegar até o aluno, se ele não está chegando. (PROFESSOR 2).

Veiga nos ajuda a compreender o processo de ensinar mediado por interações:

O processo didático tem por objetivo dar resposta a uma necessidade: ensinar. $O$ resultado do ensinar é dar respostas a uma outra necessidade: a do aluno que procura aprender. [...] Esse processo não se faz de forma isolada. Implica interação entre sujeitos ou entre sujeitos e objetos. (VEIGA, 2006, p. 13).

Os professores iniciantes, em suas respostas, demonstraram preocupação com a aprendizagem dos estudantes e destacaram que a comunicação entre os sujeitos envolvidos nesse processo deve ser acessível, coerente com o contexto e no nível dos estudantes.

Rios (2008) lembra que a aula não é algo que se dá, mas algo que se faz nas relações entre professor e alunos e conclui que quando "se faz aula" se ensina, ou seja, quando professor e aluno se implicam em construir aulas, o ensino (e provavelmente a aprendizagem) é consequência.

No que se refere a conhecer os alunos também são valiosas as considerações feitas por Pimenta e Anastasiou (2008, p. 232), ao analisarem pesquisas desenvolvidas por outros investigadores do ensino superior sobre as características atuais do aluno universitário. As autoras chamam a atenção para a necessidade de se "[...] identificar quem são os alunos com os quais se compartilhará um semestre ou ano letivo e que participarão no projeto da instituição em que se inserem, nessa rica e preciosa etapa de suas vidas." 
Um dos respondentes afirmou que Há momentos em que preciso ter sensibilidade suficiente para perceber que devo tratar o assunto com calma, pois [os alunos] se encontram cansados, desanimados, descrentes. Em outros, preciso ser mais contido, severo, a fim de [...] suscitar o interesse. (PROFESSOR 22).

Podemos entender que esse professor reconhece que o ensino "envolve elementos articulados: o professor, o estudante e o conhecimento", na formulação de Veiga (2006, p. 14). A mesma fala também revela que o professor aprende ou aprimora a sua forma de ensinar a partir das práticas que desenvolve. Nesse sentido, recorremos a Marcelo Garcia (2009, p. 4) quando destaca que os "[...] professores iniciantes necessitam possuir um conjunto de ideias e habilidades críticas, assim como a capacidade de refletir, avaliar e aprender sobre seu ensino, de forma a melhorar continuamente como docentes. ${ }^{4 \prime}$

Em muitas das respostas dos entrevistados também foi possível detectar sua preocupação em procurar estar ao lado dos estudantes e não impor uma relação hierárquica. Disseram: busco sempre manter uma relação horizontal mostrando que somos iguais [...] sem precisar apelar para alguma espécie de 164 'hierarquia' ou poder de ser professor. (PROFESSOR 24). Também salientaram: tento sempre me colocar junto a eles e não à frente (PROFESSOR 23); e que o professor deve se posicionar no lado do outro, de alguém que não teve toda a experiência dele, de alguém mais jovem, ou não. [...] o professor deve tentar se colocar na posição deles e pensar que tipo de bagagem essas pessoas trazem. (PROFESSOR 19).

Esses depoimentos enfatizam o respeito ao conhecimento que o aluno traz para a escola e nos remetem a Freire (1996, p. 33), que argumenta que "[...] ensinar exige respeito aos saberes dos educandos."

As expressões dos respondentes reforçam a ideia de que o professor que se preocupa com o ensino que desenvolve, e deseja que seus alunos aprendam, deve reconhecer que o aluno, ao ingressar na universidade, traz consigo uma bagagem de conhecimentos adquiridos ao longo de sua trajetória escolar. Como afirma Zabalza:

Os alunos aprendem por meio de um processo que vai enriquecendo progressivamente os conhecimentos que já tinham. Não se parte do nada; na universidade menos ainda. Ela recebe 
indivíduos com uma bagagem de conhecimentos e experiências muito grande, motivo pelo qual superam todos os níveis do processo escolar. Isso não quer dizer que eles não continuem apresentando pontos fortes e fracos quanto a seus conhecimentos, mas neste momento começa seu processo de aprendizagem universitária, retomando o que já têm e enfrentando aquilo de que carecem. Não se abre, nesse sentido uma etapa nova e separada das anteriores: os alunos continuam sua formação em um novo contexto, com um novo marco de exigências e expectativas. (ZABALZA, 2004, p. 1951.

Complementarmente a isso, destacamos as expressões de nossos entrevistados quando disseram que [eu] respeito a construção de cada sujeito e a história que cada um traz de si (PROFESSOR 27); ou: Tento [...] permitir uma troca de conhecimentos e não a transmissão de saberes. (PROFESSOR 23). Podemos ler, nessas falas, que esses professores percebem que "[...] ensinar não é transferir conhecimento, mas criar as possibilidades para a sua produção ou a sua construção." (FREIRE, 1996, p. 25).

Outro professor referiu que Eles [os alunos] têm espaço para suas manifestações, reivindicações, opiniões e eu também. (PROFESSOR 18). Percebemos que o professor compreende a sala de aula como um espaço de aprendizagem, estimulando a exposição das concepções e compreensões dos alunos sobre o conteúdo. A esse respeito, Zabalza ensina:

Aprender é conversar: recriamos nosso próprio discurso à medida que interagimos com o discurso alheio, ou seja, o que os outros dizem ou fazem modifica o que eu mesmo digo ou faço; caso contrário, isso não seria um diálogo em que cada um intervém sem considerar o que o outro diz e sem mesmo considerar o que dissemos em fases anteriores da conversa, agindo à margem das condições que o próprio contexto determina. A aprendizagem, desse modo, é um processo mediado pela interação com o meio e com as pessoas que fazem parte dele, especialmente professores e colegas. (ZABALZA, 2004, p. 194).

Há indícios de que a aula desenvolvida por esse professor e seus alunos é uma aula dialógica - entendida na perspectiva freiriana - onde os conhecimentos e a voz dos alunos são valorizados e o professor não se assume como detentor de todo o conhecimento. 
Ainda em relação aos aspectos acadêmicos foi possível perceber distintas expressões, mas que convergem para o cuidado com o conhecimento que é preciso ser ensinado. Dizem eles: não é por ser professor que a gente vai dominar o conhecimento. Ninguém domina o conhecimento inteiro, nunca. Quanto mais a gente estuda mais a gente sabe e mais a gente sabe o quanto a gente não sabe (PROFESSOR 9); ou o professor é também estudante, essa é uma condição para construir o saber. (PROFESSOR 25). Revelam que o professor, assim como o aluno, é um sujeito que aprende. Entretanto, mesmo que o professor expresse que "ninguém domina o conhecimento inteiro", é possível inferir que ele se percebe responsável por parte do conhecimento que precisa ensinar aos alunos. Também é possível afirmar que, em um contexto de sala de aula, a aprendizagem é resultado de um processo vinculado ao ensino e, portanto, ao professor que o desenvolve.

O professor que reflete sobre o que faz muda seu pensamento e suas ações frente aos alunos, reelabora sua maneira de ensinar e aprender. Como explica Gimeno Sacristán (1995, p. 76), "[...] o professor não é um técnico que se limita a aplicar corretamente um conjunto de diretivas, mas um profissional que se interroga sobre o sentido e a pertinência de todas as decisões 166 em matéria educativa." Nessa perspectiva, a sensibilidade para esse processo de reflexão possibilita que o professor entenda sua condição docente como permeada por um constante processo de aprendizado e de reconstrução das práticas educativas, o que o instiga a buscar novas formas de pensar e agir a partir das diversas situações vivenciadas no ambiente universitário.

Os professores iniciantes colaboradores da pesquisa apontaram ainda alguns desafios no que se refere aos aspectos acadêmicos das relações professor e estudantes. $\bigcirc$ mais expressivo foi a falta de comprometimento dos alunos com o processo de ensino e aprendizagem. Eles gostariam que os alunos fossem mais motivados, mais interessados em aprender, tivessem mais questões, estudassem mais, lessem mais (PROFESSOR 6); e Hoje a minha dificuldade é o desinteresse dos alunos [...] A minha principal decepção é essa, de não ver alunos centrados [...] Eles não conseguem ter foco. (PROFESSOR 10).

Revelaram que, por vezes, os alunos mostram-se desinteressados e desmotivados. Esse é um desafio que o professor enfrenta, o de chamar a atenção ou cativar o aluno para participar do processo de ensino e aprendizagem. 
A trajetória educativa dos alunos, muitas vezes, foi calcada em processos reprodutivos do conhecimento e, para alguns, a memorização dos conteúdos foi prática recorrente. Poucas vezes, possivelmente, tenham sido estimulados a uma participação e protagonismo no próprio processo de formação. É fundamental destacar o importante papel do aluno em seu próprio aprender, seja porque ao se sentir protagonista melhora seu rendimento, seja porque ele intervém como causa próxima de sua própria aprendizagem, algo que é impossível de substituir pelas estratégias de ensino. (ZABALZA, 2004).

Ao ingressarem na universidade, os alunos carregam essas representações de aula e de posicionamento, permanecendo "passivos" à espera do conteúdo a ser explanado pelo professor. Se os professores não se dispuserem a romper com essa perspectiva e seguirem apenas expondo os alunos aos conteúdos, estes se manterão pouco ativos, esperando pelo conhecimento pronto e acabado. Considerar que os alunos não são os únicos responsáveis por sua aprendizagem não significa isentá-los de um papel ativo na construção dessa aprendizagem.

A aprendizagem é um processo complexo e compartilhado. $\bigcirc$ estudante tem um papel fundamental nesse processo, pois organiza os conteúdos, processa-os e constrói com os professores os conhecimentos que lhes possibilitem agir a partir do apreendido.

Também não podemos deixar de considerar que os alunos, ao ingressarem na universidade cada vez mais cedo, talvez não tenham a maturidade necessária para fundamentar a sua escolha profissional. Esses aspectos possivelmente incidem sobre a sua falta de interesse e motivação em sala de aula.

Um dos possíveis caminhos para a superação do desafio de motivar os alunos pode ser o que Fernandes (2008) denomina de pedagogia de vínculos, que consiste no comprometer-se com o outro e ele consigo mesmo, ou seja, o professor se compromete com o ensino visando à aprendizagem do aluno e este se compromete com sua aprendizagem.

Para tanto, é importante e interessante que se proponha em aula atividades que façam sentido para as vidas dos alunos - e aqui novamente o diagnóstico das experiências vividas e dos saberes construídos pelos alunos é fundamental, especialmente no início das atividades do semestre. Pimenta e Anastasiou (2008, p. 234) enfatizam que, mesmo que se tenha de adiar o início das atividades do semestre, é necessário identificar e trabalhar sobre 
as necessidades detectadas com os alunos. De acordo com as autoras, "[...] diagnósticos simples aplicados como atividades e corrigidos coletivamente, na própria sala de aula, podem trazer indicadores que levem os próprios alunos a tomar consciência da necessidade de assumir o caminho a ser trilhado coletivamente." Nessa oportunidade, professores e alunos podem intensificar sua aproximação e construir coletivamente um contrato de (co)responsabilização pela aprendizagem.

Outro aspecto envolvido na pesquisa tomou as relações pessoais envolvendo professor e estudantes como um elemento chave na construção da docência. Veiga afirma que para "[...] o professor concretizar seu ato de ensinar de forma satisfatória, o vínculo afetivo é uma dimensão indispensável, uma vez que emoções, interesses pessoais, sonhos permeiam toda a relação pedagógica." (VEIGA, 2006, p. 24).

A maioria dos professores iniciantes colaboradores desta pesquisa mencionou ter uma boa relação com os estudantes, sem conflitos ou problemas. Um professor lembrou que as relações podem exigir algum tempo e investimento. Esta relação nunca é tão boa no início. Acho que a primeira impressão não é das melhores. A relação tende a ser ótima ou excelente com 168 os estudantes e turmas que tenho um contato maior, ou seja, uma relação mais longa. (PROFESSOR 26). Esse professor reconhece que uma boa relação entre professor e alunos requer aproximação, requer conhecer o educando, sua realidade. Ele reconhece também que essa boa relação não é instantânea, é um processo de conquista. Para outros, foi complexo definir a intensidade e características dessa relação.

Talvez essa seja uma condição própria do professor iniciante, que tem de modular a proximidade necessária com a autoridade que gostaria de exercer. Um deles afirmou: Eu acho que a relação é boa. Não é muito uma relação de amizade. Eu não tenho essa proximidade muito grande com eles [...] Eu acho a minha relação aberta e boa, mas sem muita proximidade, é uma coisa minha, de personalidade mesmo. (PROFESSOR 6). Entendemos, a partir de Libâneo (1993), que o professor aproxima-se dos alunos, mas não quer que sua relação com os mesmos se caracterize como uma "relação maternal ou paternal", ou seja, ao mesmo tempo que estabelece vínculos e aproximações com os alunos, não quer ver perdidos o respeito e sua autoridade, enquanto qualidades intelectuais, morais e técnicas. 
Outros professores destacaram aspectos emotivos, de amizade, de bem-estar quando falaram de suas relações com os alunos: tento sempre buscar com que os espaços em sala e fora de sala, sejam prazerosos, instigantes e dialogados (PROFESSOR 27); ou: [percebo nessa relação a] necessidade do humor, da ironia, da crítica, da amizade (PROFESSOR 22); ou ainda: Eventualmente gosto de fazer uma brincadeira, que é para dar uma descontraída. (PROFESSOR 1). Esses professores, possivelmente, sentem-se realizados, satisfeitos, felizes com o ensino que desenvolvem e com as relações que estabelecem com seus alunos. Conseguem exercitar a condição que aponta Freire (1996) quando propõe que ensinar exige alegria, ensinar exige criticidade, ensinar exige querer bem aos educandos. Também Veiga colabora na mesma direção:

Ensinar como um ato afetivo se expressa por meio de elos da afetividade, que favorecem uma troca entre professor e os alunos. Vivenciar um ensino permeado pela afetividade significa o fortalecimento de um processo de conquista para despertar o interesse do aluno [...] para o professor desempenhar sua função de ensinar de forma satisfatória, o vínculo afetivo é imprescindível para tornar a sala de aula um ambiente mais humanizado, mais próximo às características e necessidades dos alunos. [...] Isso conduz à afetividade saudável, necessária ao convívio e à redução da tensão. (VEIGA, 2006, p. 22-23).

Chamamos atenção, também, para o fato de os professores iniciantes, muitas vezes, mencionaram a necessidade do diálogo, de ouvir os alunos. Esse aspecto converge com os apontamentos de Freire (1996) quando este pondera que ensinar exige saber escutar e ter disponibilidade para o diálogo. A presença do diálogo nos processos de ensino e de aprendizagem também nos remete à amizade, à compaixão, à compreensão do outro, ao reconhecimento de que são seres humanos os sujeitos desses processos, portanto detentores de sentimentos e de carências. (FERNANDES, 2008). Certamente, essa condição exige saberes próprios da docência, da natureza do trabalho do professor.

No caso dos iniciantes, é comum haver uma proximidade de idade e de tempo escolar com os alunos, como destacou um professor: Tenho uma relação muito boa com os estudantes, talvez por não estar muito longe deles, tanto na idade quanto em tempo como docente. Também era aluno há não muito tempo atrás, o que faz com que eu entenda bem suas angústias, inseguranças, 
anseios e comportamentos. (PROFESSOR 24). Esse professor iniciante, como todos os outros colaboradores deste estudo, não tiveram uma preparação ou formação específica para ser professor, mas todos revelaram que as muitas horas de observação como estudantes contribuíram para a construção de suas referências acerca do ensino e lhes ajudam a interpretar suas experiências. (GARCIA, 2009). Freire também realça esse aspecto ao mencionar:

É interessante observar que a minha experiência discente é fundamental para a prática docente que terei amanhã ou que estou tendo agora simultaneamente com aquela. É vivendo criticamente a minha liberdade de aluno que, em grande parte, me preparo para assumir ou refazer o exercício de minha autoridade de professor. (FREIRE, 1996, p. 100).

Por outro lado, esse mesmo fator de proximidade de idade e de tempo escolar entre professor e alunos pode ser um desafio. Minha maior dificuldade, no início, era lidar com os alunos mais velhos do que eu, com mais experiência de vida e posições menos flexíveis. A proximidade de idade entre eu e eles ora é facilidade ora dificuldade na relação. (PROFESSOR 23). Percebemos que

170 as interações estabelecidas entre esses sujeitos não estão livres de conflitos ou tensões.

\section{Professores iniciantes avaliando a preparação para a docência recebida em Programas de Pós-Graduação}

Foi importante, no prosseguimento da investigação, entender como os professores universitários iniciantes percebiam então a preparação ${ }^{5}$ que tiveram para a docência, frente aos desafios mencionados.

Os Programas de Pós-Graduação stricto sensu são o lugar procurado por profissionais que pretendem ingressar na carreira do magistério superior para se qualificarem para a docência, em concordância com o que apregoa a Lei de Diretrizes e Bases da Educação Nacional de 1996 (LDB, 1996). Ao mesmo tempo que cumprem o processo de formação valorizado na carreira docente, atingindo o grau de mestre e/ou doutor, satisfazem a necessidade de conhecimentos específicos ligados à sua futura área de atuação como docentes. No entanto, esses programas possuem sua base na dimensão da pesquisa 
e em um recorte específico da área do conhecimento sem, em geral, preocuparem-se com os saberes próprios da docência. Essa condição faz com que a maioria dos ingressantes na carreira do magistério superior careça de base formativa no que se refere aos conhecimentos profissionais para a docência.

Nossos respondentes perceberam que sua formação na pós-graduação se dirigiu à pesquisa, havendo pouca preocupação com a docência e com o enfrentamento das complexidades da aula universitária. Ainda que não generalizada essa foi uma crítica recorrente e, portanto, aponta para uma condição que merece atenção. Disse-nos um entrevistado que o desafio da prática docente não é nem de longe abordado em programas de pós-graduação, pelo menos da área da qual vim. Trabalhamos pesquisa e publicação de teses e artigos. Em minha opinião, há um buraco enorme nessa formação. (PROFESSOR 24). Outro docente deu o seguinte depoimento: concordo que a pós-graduação stricto sensu pode ser um dos lugares da formação do professor universitário. No entanto, tomando meu exemplo, não foi. O tempo cruelmente escasso para desenvolvimento da pesquisa, sequestrado por um sistema nacional que 'atesta qualidade da pós-graduação' por quantidade de trabalhos publicados, leva os futuros professores a tomar um único caminho, sem escoIhas, como em um regime totalitário. (PROFESSOR 25).

A incorporação ao mundo da pesquisa, na maior parte das vezes, ocorre em um contexto muito específico e regulado. Zabalza (2004) argumenta que as competências e qualidades profissionais para o ensino e para a pesquisa são diferentes. Para o autor, o trabalho docente envolve vários tipos de conhecimentos e competências que necessitam de uma preparação específica.

Reconhecemos a pesquisa como parte substancial da docência superior, porque ajuda os professores a pensar e a compreender o conhecimento como relativo e em movimento. A pesquisa é fundamental para subsidiar o processo de construção do conhecimento, para organizar o currículo e as áreas de estudo, de modo que no diálogo da empiria com o sistematizado sejam criadas condições para novas construções que superem o instituído. A universidade, no entanto, vem atribuindo um maior status acadêmico à pesquisa até transformá-la no componente básico da identidade e do reconhecimento do docente universitário. Fez com que o ensino se transformasse em uma atividade secundária dos docentes. Muitas vezes, na universidade se aceita que pesquisar constitui um nível de desenvolvimento intelectual superior, uma capacidade 
para ver as coisas de forma mais rigorosa e sistemática, um maior conhecimento dos assuntos que transitam nos campos científicos. Em contrapartida, essa argumentação é fraca se analisada sob a ótica do ensino. (CUNHA, 20111.

A universidade estaria cumprindo com uma parcela de sua função no que diz respeito à pesquisa - se o docente fosse orientado para produzir conhecimento através desta, buscando o equilíbrio entre o conteúdo social e a excelência acadêmica, com um claro comprometimento com a elevação das condições de vida da população, em integração com o entorno social onde se situa.

Em suma, os entrevistados mostraram preocupação em relação à formação pedagógica, pois, nos seus cursos de mestrado e/ou de doutorado, não tiveram oportunidades de discutir o ensino. Afirmaram que esses cursos estão muito voltados para a formação do pesquisador e pouca ou nenhuma preocupação é vislumbrada no sentido da preparação do professor para enfrentar os desafios da sala de aula. Explicaram que seus cursos de graduação foram balizados na perspectiva técnica e, posteriormente, a pós-graduação foi alicerçada na investigação de problemas muito específicos - aspectos esses que

172 limitaram significativamente sua prática pedagógica.

É possível inferir, a partir das respostas dos entrevistados, que não existiu também a preocupação em relacionar ensino e pesquisa nos cursos de pós-graduação que fizeram. Essa condição fez com que, consequentemente, não encontrássemos nas respostas dos professores iniciantes a relação entre ensino e pesquisa desenvolvida em suas práticas pedagógicas.

\section{Conclusões}

Uma das consequências da expansão do ensino superior no Brasil foi a contratação de um corpo docente constituído na sua maioria de recém-doutores e/ou mestres que realizaram sua formação acadêmica e, imediatamente, ingressaram na carreira docente. Mais do que nunca, a seleção dos docentes está privilegiando a titulação e a produção acadêmica dos candidatos.

Essa foi uma das premissas que nos impulsionaram a desenvolver um estudo com o objetivo de compreender, através das expressões de professores iniciantes, a relação que os mesmos têm com os alunos quando se inserem na 
carreira universitária e a percepção sobre sua preparação para a docência. O percurso investigativo possibilitou a compreensão dos processos vivenciados pelos docentes e favoreceu inferências sobre a realidade que analisamos.

Mesmo assumindo que os achados são sempre provisórios, é possível reafirmar a condição da complexidade da docência. Nossos interlocutores perceberam que a preparação para a docência universitária exige mais do que o aprofundamento teórico de sua especialidade e enfatizaram que essa preparação não acontece em cursos de pós-graduação stricto sensu. Observamos que os professores, ao fazerem sua formação em programas de pós-graduação, de modo geral construíram uma competência técnico-científica em alguma especificidade de seu campo de conhecimento, mas pouco avançaram rumo a uma visão pedagógica mais ampla, necessária para sua inserção e desenvolvimento profissional.

Julgamos importante ressaltar que os professores iniciantes, talvez pela pouca diferença de idade entre eles e seus alunos, preocupam-se em estabelecer sua autoridade docente frente aos estudantes, mas se mostram atentos e sensíveis em relação às exigências complexas que se fazem presentes na relação professor-aluno e ao (re)conhecimento das realidades onde desenvolvem suas práticas pedagógicas. Não deixaram de reconhecer e enfatizar que encontram dificuldades para mobilizar seus alunos para viver os processos de ensinar e aprender de forma mais autônoma, entretanto empenham-se para que aconteça esse processo.

É possível inferir que os cursos de pós-gradução, que, de acordo com a LDB/96, são responsáveis pela preparação dos professores universitários, têm priorizado o desenvolvimento de pesquisas e pouco ou nada têm oferecido ao pós-graduando em termos de preparação para a docência. Mesmo que não intencionalmente, reproduzem a situação em que as atividades de ensino e pesquisa são realizadas de modo dissociado, perpetuando a ideia de que, para ser professor do ensino superior, basta ser bom pesquisador.

Essas conclusões não têm a intenção de tornarem-se verdades, porém entendemos que são apontamentos que podem contribuir com o conhecimento na área da pedagogia universitária e estimular outros estudos nessa direção. 


\section{Notas}

1 Estamos nos referindo à formação necessária para o profissional de diferentes áreas de atuação e de pesquisa exercer a docência, sem negar, com isso, a importância e necessidade dos conhecimentos específicos de sua área.

2 A amostra ficou assim distribuída: 9 (nove) professores da UFPel, 6 (seis) professores da UNIPAMPA, 6 (seis) professores da UNISINOS e 6 (seis) da UFPR - Setor Litoral. Os professores entrevistados assinaram o termo de consentimento. Optamos por não identificá-los no texto.

3 Foram entrevistados docentes com formação básica nos Cursos de Nutrição, Engenharia Madeireira, Odontologia, Biologia, Medicina, Agronomia, Engenharia Agrícola, Matemática, Engenharia Florestal, Agroecologia, Gestão Ambiental, Administração, Ciência da Computação, Enfermagem, Engenharia de Minas, História, Linguística e Farmácia.

4 Tradução nossa.

5 Conforme Lei 9.394/96, Artigo 66: A preparação para o exercício do magistério superior far-se-á em nível de pós-graduação, prioritariamente em programas de mestrado e doutorado. Igrifo das autoras).

\section{Referências}

BARDIN, Laurence. Análise do discurso. Lisboa. Edições 70, 1979.

BRASIL. MEC/INEP. Censo da Educação Superior 2010. Censup: Brasília, 2011.

Presidência da República. Casa Civil. Subchefia para Assuntos Jurídicos. Lei $n^{\circ}$ 9.394, de 20 de dezembro de 1996. Estabelece Lei de Diretrizes e Bases da Educação Nacional. Disponível em: <http://portal.mec.gov.br/arquivos/pdf/ldb.pdf>. Acesso em: 19 set. 2013.

CUNHA, Maria. Isabel da. Indissociabilidade entre ensino e pesquisa: a qualidade da graduação em tempos de democratização. Revista Perspectiva, Florianópolis v. 29, n. 2, p. 443-462, jul./dez. 2011.

FERNANDES, Cleoni Maria Barboza. A procura da senha da vida - de-senha a aula dialógica? In: VEIGA, Ilma Passos de Alencastro (Org.). Aula: gênese, dimensões, princípios e práticas. Campinas, Papirus, 2008.

EDITORIAL. Folha de S. Paulo, São Paulo, p. 2, 10 nov. 2011.

FREIRE, Paulo. Pedagogia da autonomia: saberes necessários à prática educativa. 4. ed. São Paulo, SP: Paz e Terra, 1996.

LIBÂNEO, José Carlos. Didática. São Paulo: Cortez, 1993. 
GARCIA, Carlos Marcelo. Los comienzos en la docencia: un profesorado con buenos principios. Profesorado: Revista de Curriculum Y Formación Del Profesorado, Granada (España), v. 13, n. 1, p. 1-25, jan./abr. 2009. Disponível em: <http://www.ugr.es/ recfpro/ rev131ART1.pdf>. Acesso em: 19 set. 2013.

PIMENTA, Selma Garrido; ANASTASIOU, Léa das Graças Camargo. Docência no ensino superior. São Paulo: Cortez, 2008.

PROFESSOR 1. Entrevista oral. Pelotas (Rio Grande do Sul), out. 2010.

PROFESSOR 2. Entrevista orall. Pelotas (Rio Grande do Sul), out. 2010.

PROFESSOR 3. Entrevista oral. Pelotas (Rio Grande do Sul), out. 2010.

PROFESSOR 4. Entrevista oral. Pelotas (Rio Grande do Sul), out. 2010.

PROFESSOR 5. Entrevista oral. Pelotas (Rio Grande do Sul), out. 2010.

PROFESSOR 6. Entrevista oral. Pelotas (Rio Grande do Sul), out. 2010.

PROFESSOR 7. Entrevista oral. Pelotas (Rio Grande do Sul), out. 2010.

PROFESSOR 8. Entrevista oral. Pelotas (Rio Grande do Sul), out. 2010.

PROFESSOR 9. Entrevista oral. Pelotas (Rio Grande do Sul), out. 2010.

PROFESSOR 10. Entrevista oral. São Leopoldo (Rio Grande do Sul), out. 2010.

PROFESSOR 11. Entrevista oral. São Leopoldo (Rio Grande do Sul), out. 2010.

PROFESSOR 12. Entrevista oral. São Leopoldo (Rio Grande do Sul), out. 2010.

PROFESSOR 13. Entrevista oral. São Leopoldo (Rio Grande do Sul), out. 2010.

PROFESSOR 14. Entrevista oral. São Leopoldo (Rio Grande do Sul), out. 2010.

PROFESSOR 15. Entrevista oral. São Leopoldo (Rio Grande do Sul), out. 2010.

PROFESSOR 16. Entrevista oral. Jaguarão (Rio Grande do Sul), out. 2010.

PROFESSOR 17. Entrevista oral. Jaguarão (Rio Grande do Sul), out. 2010.

PROFESSOR 18. Entrevista oral. Jaguarão (Rio Grande do Sul), out. 2010.

PROFESSOR 19. Entrevista oral. Jaguarão (Rio Grande do Sul), out. 2010.

PROFESSOR 20. Entrevista oral. Jaguarão (Rio Grande do Sul), out. 2010. 
PROFESSOR 21. Entrevista oral. Jaguarão (Rio Grande do Sul), out. 2010.

PROFESSOR 22. Entrevista oral. Matinho (Paraná), out. 2010.

PROFESSOR 23. Entrevista oral. Matinhos (Paraná), out. 2010.

PROFESSOR 24. Entrevista oral. Matinhos (Paraná), out. 2010.

PROFESSOR 25. Entrevista oral. Matinhos (Paraná), out. 2010.

PROFESSOR 26. Entrevista oral. Matinhos (Paraná), out. 2010.

PROFESSOR 27. Entrevista oral. Matinhos (Paraná), out. 2010.

RIOS, Terezinha de Azevedo. A dimensão ética da aula ou o que fazemos com eles? In: VEIGA, Ilma Passos de Alencastro (Org.) Aula: gênese, dimensões, princípios e práticas. Campinas, Papirus, 2008.

SACRISTÁN, José Gimeno. Consciência e Ação sobre a Prática como Libertação Profissional dos Professores. In: NÓVOA, António (Org.). Profissão professor. Portugal: Porto Editora, 1995.

VEIGA, Ilma Passos de Alencastro. Ensinar: uma atividade complexa e laboriosa. In: VEIGA, 176 Ima Passos de Alencastro (Org.). Lições de didática. Campinas, SP: Papirus, 2006.

ZABALZA, Miguel Ángel. $\mathbf{O}$ ensino universitário: seu cenário e seus protagonistas. Porto Alegre: Artmed, 2004.

Profa. Dra. Beatriz Maria Boéssio Atrib Zanchet Universidade Federal de Pelotas | Rio Grande do Sul Departamento de Ensino Grupo de Pesquisa Pedagogia Universitária: Formação de professores E-mail | biazanchet@gmail.com 
Profa. Ms. Nadiane Feldkercher Universidade Federal de Pelotas | Rio Grande do Sul Estudante do curso de Doutorado em Educação pela Bolsista | CAPES | PDSE Grupo de Pesquisa Pedagogia Universitária: Formação de professores E-mail | nadianef@gmail.com

Profa. Dra. Helena Beatriz Mascarenhas de Souza Universidade Federal de Pelotas | Rio Grande do Sul Grupo de Pesquisa Pedagogia Universitária: Formação de professores E-mail | bitisamascarenhas@hotmail.com

Recebido 26 set. 2013 Aceito 19 dez. 2013 